\title{
AUTOMATED COMPLEX PROJECT ON THE ORGANIZATION CLAIM WORKS WITH FUEL
}

\author{
Vadim Kleshnya ${ }^{1}$, Elena S. Vorontsova ${ }^{1, *}$, and Tatyana S. Taylasheva ${ }^{1}$ \\ ${ }^{1}$ Tomsk Polytechnic University, 634050 Tomsk, Russia
}

\begin{abstract}
Consideration of problems with the quality of the account and the amount of fuel in the power plant. It is proposed to create an automated system that includes forms of documents, promptly filled energy facility staff, as well as related economic calculations. Consideration of the algorithm of reference works on fuel, laid in the automated system. Compiled by doing work scheme with the fuel.
\end{abstract}

\section{Introduction}

When the flow of fuel to the plant, an important point, that's will happened when working with him is the quantity and quality of the fuel. It is worth noting that there is now virtually no technical means for carrying out qualitative and representative input and control of fuel. In particular, the volume of mechanized input quality control of solid fuels to energy facilities is not more than $10 \%$ [1]. In addition, there is no certified fuel laboratory with the possibility of using the results to conduct claim activities [2].

Another problem is that most businesses, there is no established system of acceptance of a service fuel and Legal Department of the company. And thus, the organization claims to be considered the work of high quality limited.

The efficiency claim work in greater influence compliance deadlines for filing claims (table 1), which in turn depend on the timing of the acceptance of the fuel quantity (10 days) and quality (20 days).

Table 1. Presentation of claims [4].

\begin{tabular}{|c|c|c|}
\hline Type of claim & Respondent & Time \\
\hline \multicolumn{3}{|c|}{ Solid and liquid fuels } \\
\hline \multirow[t]{2}{*}{ Due to fuel shortage } & Carrier & 6 months \\
\hline & Supplier & 1 month \\
\hline By supplying poor quality fuel & Supplier & 1 month \\
\hline Frozen fuel supply & Supplier & 1 month \\
\hline For delay in supply of fuel & Supplier & 2 months \\
\hline For delay in delivery of fuel & Carrier & 45 days \\
\hline By fuel, the lost in transit & Carrier & 6 months \\
\hline \multicolumn{3}{|c|}{ Gas fuel } \\
\hline Quantity & Supplier & By contract \\
\hline
\end{tabular}

\footnotetext{
*Corresponding author: ves@tpu.ru
} 


\begin{tabular}{|l|l|c|}
\hline Quality & Supplier & 1 month \\
\hline For mismatch pressure & supplier & 1 month \\
\hline For failure & supplier & By contract \\
\hline
\end{tabular}

In order to avoid problems arising from the need to observe the algorithm of reference works on fuel [3] that in the future will greatly facilitate their implementation and facilitate efficient and reliable operation of thermal power equipment.

\section{Results}

It is proposed to create an automated system that includes forms of documents, promptly filled energy facility staff, as well as related economic calculations. The diagram is shown (Fig. 1) reflects the algorithm of works on fuel, laid in the automated system.

The scheme is divided into two main blocks: technical and economic. Technical block includes an input control in the enterprise, which is divided into the control of fuel quantity and quality.

By controlling the number of fuel include documents [4]:

- Protocol mass evaluation;

- A statement of account;

- Transport documents (waybill, invoice, etc.);

- Calculation permissible weight differences.

By monitoring fuel quality [4]:

- Certificate of quality (quality certificate);

- Minutes of quality assessment indicators;

- Control sampling instrument;

- Transport documents (waybill, invoice, etc.).

If the fuel meets all the requirements for documents control of quantity and quality, it is drawn up acceptance certificate, and then the fuel is used in the power plant.

If the fuel has a deviation in the amount of shortage of fuel is drawn up, there is a calculation value of the missing fuel and put up claims as the carrier and the supplier.

The presence of deviations in quality is considered separately from the vendor and separate from the carrier. The incoming fuel poor quality shall be drawn on the actual fuel, there is a calculation of this cost of fuel and put up a claim to the supplier. Arriving at the energy company in the frozen state of the fuel also includes a procedure for preparation of the report of the arrival of the frozen fuel going assessment of the rolling stock and the cost of delay paths exhibiting claims to the carrier. The economic unit is a check violation of terms of delivery. Fuel which has no deviations shall be drawn as fuel acceptance and in the future it is used in power plants.

Depending on such deviations as "did not come the whole party", "not delivered part of the party", "lost in transit", is drawn up violating the terms of the supply of fuel. Further, there is also a penalty for delay estimation and invoicing vendor claims. With regard to the refusal of recognition and claim after the procedure in two blocks in the event of failure by one of the parties claims documents for its consideration and the proceedings are sent to the Arbitration Court of the Russian Federation. In the event that claims are considered options such as the return of the fuel supplier, selling to a third party, the use of fuel in the power plant. 


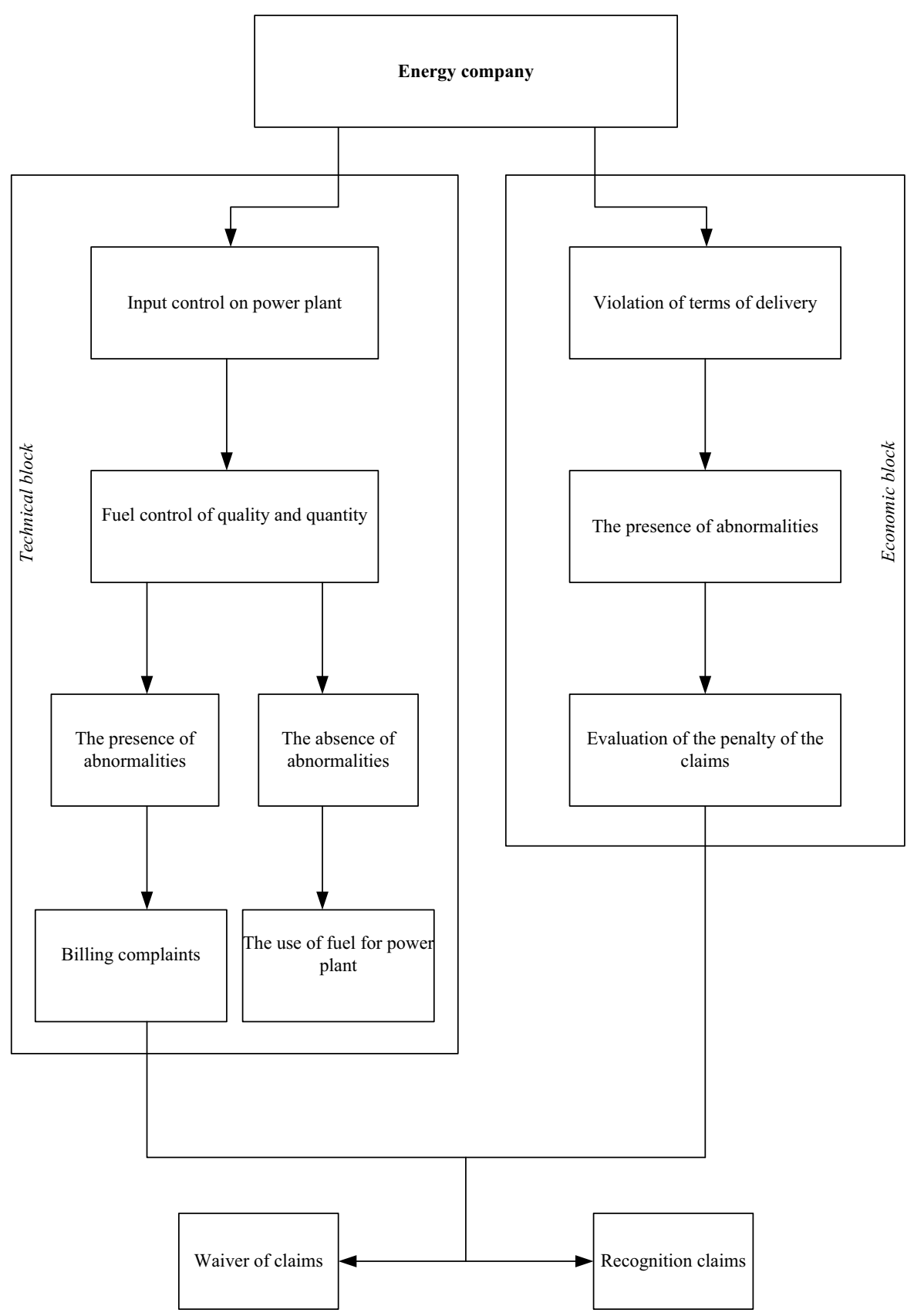

Fig. 1. Driving conduct work with the fuel in the power plant. 


\section{Conclusion}

The possibilities of modern information technology allow you to create a new generation of software systems that have the flexibility and scalability that helps regular updating of the regulatory framework. At the moment the authors of the article set of documentation collected, necessary for the realization of the creation of the automated complex. The determining factor in the use of the automated complex in the energy company is to improve the quality of doing work on the fuel having the technical and legal in nature, according to the following criteria:

1. Reduction of the time and to perform certain operations on the collection and processing of data;

2. Improving staff efficiency;

3. Error-free and timely filling of documents;

4. Updating of normative and technical documentation on all sides;

5. Increasing the level of control and performance discipline;

6 . Reducing the risk of deterioration or interruption of power equipment in the presence of any wrongdoing.

\section{References}

1. V. Kazakov, P. Mingalev, D. Linev, Input control of the solid fuel quality in the Russian power, 6, 27 (2015)

2. S. Remes, V. Edelman, E. Govsievich, R. Alechinsky, Recommendations to improve the work with claims on fuel at thermal power plants of RAO "EEC of Russia", 10, 4 (2006)

3. V. Kleshnya, V. Vorontsova, T. Taylasheva, The demand of the organization of reference works with a fuel in the power plant, 2, 83 (2016)

4. CO 34.44.223. Recommendations for claims work on fuel [in Russia] 